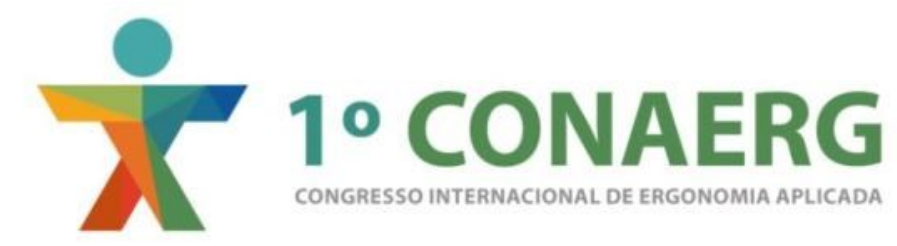

\title{
ASPECTOS ERGONÔMICOS ALIADOS A FERRAMENTAS DIGITAIS APLICADOS NA READEQUAÇÃO DE CARTEIRAS ESCOLARES
}

\author{
Gustavo Antunes de Souza; \\ Marina Elisabete Juncioni Cruz. \\ UNIVAP - Universidade do Vale do Paraíba, Arquiteto e Urbanista. \\ e-mail:gustavo.antunes2009@bol.com.br \\ UNESP - Universidade Estadual Paulista, Arquiteta e Urbanista, Especialista em \\ Engenharia de Segurança do Trabalho. \\ e-mail: marina.juncioni@gmail.com
}

\begin{abstract}
RESUMO
O presente artigo aborda a readequação e o reprojeto de uma carteira escolar para uma escola de ensino técnico na cidade de Mogi Guaçu/SP. O mobiliário escolar é de ampla relevância para o processo educacional, pois um mobiliário inadequado não dará conforto físico e psicológico ao aluno, prejudicando sua concentração, comportamento e produtividade. Fundamentado em estudos de ergonomia, antropometria, biomecânica e normas técnicas, analisou-se os diferentes modelos de carteiras existentes na escola em questão, e nenhuma delas atende ergonomicamente aos alunos. Consequentemente, foi possível desenvolver um projeto de mobiliário confortável ergonomicamente, atendendo as diferentes características antropométricas dos alunos.
\end{abstract}

Palavras-chave: Ergonomia. Carteira Escolar. Reprojeto.

\begin{abstract}
This article discusses the upgrading and redesigning a school desk for a technical education school in the city of Mogi Guaçu / SP. The school furniture is of wide relevance to the educational process as inadequate furniture will not give physical and psychological comfort to the student, impairing concentration, behavior and productivity. Based on ergonomic studies, anthropometry, biomechanics and technical standards, we analyzed the different models of existing portfolios in the school in question, and none of them meets ergonomically students. Consequently, it was possible to develop a comfortable furniture design ergonomically, meeting the different anthropometric characteristics of students.
\end{abstract}

Keywords: Ergonomics. School Desk. Redesigning. 


\section{INTRODUÇÃO}

O mobiliário escolar é parte fundamental ao processo de aprendizagem, conforme afirma Bergmiller et al. (1999), portanto tal contexto irá influenciar de forma direta na aprendizagem. A maioria das cadeiras e carteiras, destinadas aos alunos, disponíveis nas escolas sofrem a falta de respaldos normativos por não estar inserida em um contexto industrial, isso segundo Paschoarelli (1997), o que acarreta danos de bem-estar físico, psicológico, social e educacional ao educando, devido principalmente à falta de atenção ergonômica a tais mobiliários. Neste âmbito de pesquisa dois fatores são fundamentais, a antropometria como a ciência que estuda as medidas do corpo humano (IIDA, 2010; GRANDJEAN, 1998), e a ergonomia que por meio de métodos e técnicas científicas colaboram para as melhorias dos processos, de produtividade, bem como aos ambientes de trabalho e estudo.

Portanto, tal artigo visa o levantamento das carteiras escolares de uma escola técnica situada na cidade de Mogi Guaçu - SP, resultando assim a uma proposta de readequação destes mobiliários, por meio de ferramentas computacionais, e que prezem os principais aspectos ergonômicos.

\section{CONTEÚDO}

As primeiras teses relacionadas à ergonomia no Brasil ganhou destaque a partir da década de 1960 pela Universidade de São Paulo, porém pouco se pesquisou sobre os benefícios dos estudos de ergonomia e sua aplicabilidade no ambiente escolar, principalmente se ressaltar a carga horária que um aluno fica acomodado nestes ambientes e seus respectivos mobiliários.

Tabela 1: Carga horária mínima de um estudante destinada aos ambientes escolares

\begin{tabular}{lccc}
\hline $\begin{array}{l}\text { Classificação de } \\
\text { Período de Ensino }\end{array}$ & Tempo de Ensino & Carga Horária & Total \\
\hline Educação Infantil & 1 ano & 800 horas anuais & 800 horas \\
\hline Ensino Fundamental & 9 anos & 1200 horas anuais & 10800 horas \\
\hline Ensino Médio & 3 anos & 800 horas anuais & 2400 horas \\
\hline
\end{tabular}

Fonte: Lei de Diretrizes e Bases da Educação no Brasil (1996)

É notório, que diante do histórico escolar, não é constatado nenhum móvel escolar que tenha sido planejado atendendo os critérios mínimos de ergonomia, até mesmo porque não existe um critério que atenda aos requisitos de saúde e segurança para a concepção de um mobiliário escolar. Tal constatação descrita pode ser embasada pelas Figuras 1, 2, 3 e 4 relacionadas abaixo.

Figura 1: Carteiras Escolares Chandders.

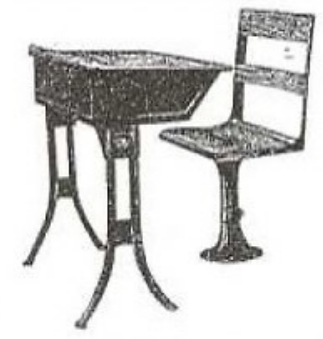

Fonte: Castro (2009)

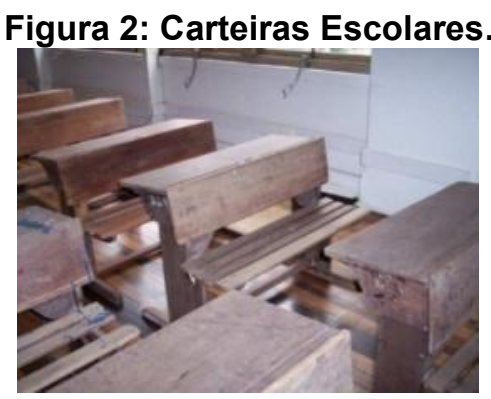

Fonte: Castro (2009) 
Figura 3: Carteira Brasil.

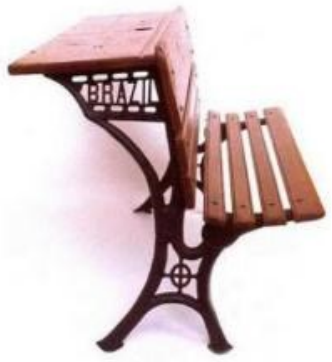

Fonte: Castro (2009)
Figura 4: Modelo Regulável.

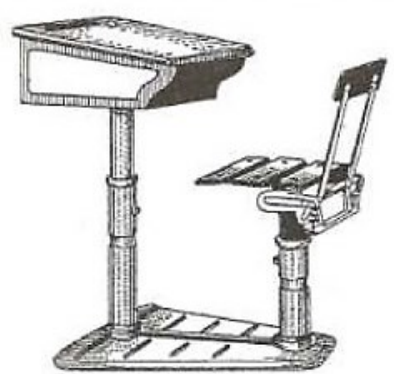

Fonte: Castro (2009)

Segundo Hira (1980), “...para o mérito do termo educacional, essas carteiras devem proporcionar a máxima função na facilidade da leitura, para qual ela deve permitir e encorajar uma boa postura de assento...", e que “... uma desconfortável postura do corpo destrói o interesse do estudante durante uma maior permanência na leitura...", deixando claro a importância das carteiras escolares de uma instituição de ensino.

\subsection{Problemáticas do Assento}

Segundo lida (2010), o corpo na posição sentado reduz a fadiga e consome menos energia, quando relacionado com a posição deste em pé, pois o peso do tronco e transferido ao assento, suavizando a pressão sobre os membros inferiores.

Os ossos denominados tuberosidades isquiáticas são os que exercem o contato do corpo com o assento de uma cadeira, vale destacar que os mesmos recebem uma camada fina de músculos, além de uma epiderme grossa.

Figura 5: Estrutura óssea da bacia, mostrando as tuberosidades isquiáticas, responsáveis pelo

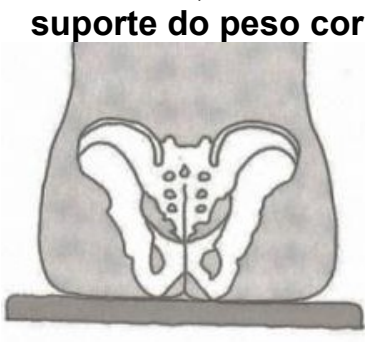

Vista frontal

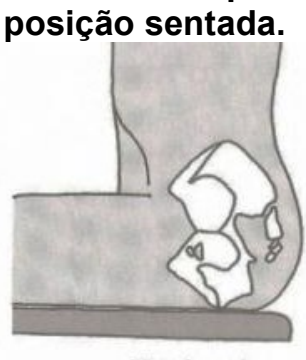

Vista lateral

Fonte: lida (2010)

Conforme lida (2010) com o propósito de suportar o peso do corpo costumava-se recomendar estofamento duro, pois permite um equilíbrio adequado do corpo, diferentemente dos estofamentos macios, porém, tal definição resulta em fadiga e dores na região das nádegas, isto devido a maior concentração da pressão na região das tuberosidades isquiáticas. Portanto o ideal é a utilização de um estofamento pouco espesso de 2 a $3 \mathrm{~cm}$ estruturado sobre uma base rígida, para suporte ao peso do corpo, e reduzindo assim a pressão máxima em cerca de $400 \%$ e aumentando a área de contato de 900 para $1050 \mathrm{~cm}^{2}$, contribuindo para a redução do desconforto e da fadiga sem prejudicar a postura. No entanto o aumento desse estofamento não melhora o conforto, ao contrário, pode prejudicá-lo. 
Figura 6: Distribuição de pressão sobre o assento.
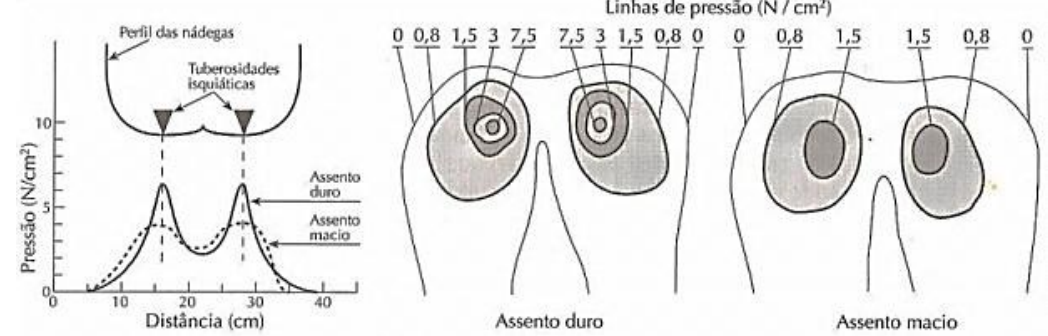

Fonte: lida (2010)

Com relação aos materiais de revestimento dos estofamentos, esses devem ter características antiderrapantes, que dissipe o suor e o calor gerados pelo ocupante, evitando assim o uso de plásticos lisos e impermeáveis.

A necessidade em inclinar a cabeça para frente possibilitando uma melhor visão provoca fadiga aos músculos do pescoço e do ombro rapidamente, isso devido ao peso da cabeça que é em torno de 4 a $5 \mathrm{~kg}$, tal postura se deve aos seguintes fatores: altura do assento demasiada; mesa baixa demais; cadeira muito longe dificultando a visualização; necessidades particulares, como por exemplo, letras muito pequenas ou uso de microscópio.

Inclinando a superfície de trabalho em pelo menos $45^{\circ}$, melhorara-se a postura do usuário, isso devido à necessidade do acompanhamento visual, e para trabalhos manuais que exigem acompanhamento visual, a superfície de trabalho pode ser inclinada em até $15^{\circ}$ para frente, ambos os casos ilustrados na Figura 7.

Figura 7: Campo de visão para leitura e trabalhos manuais.

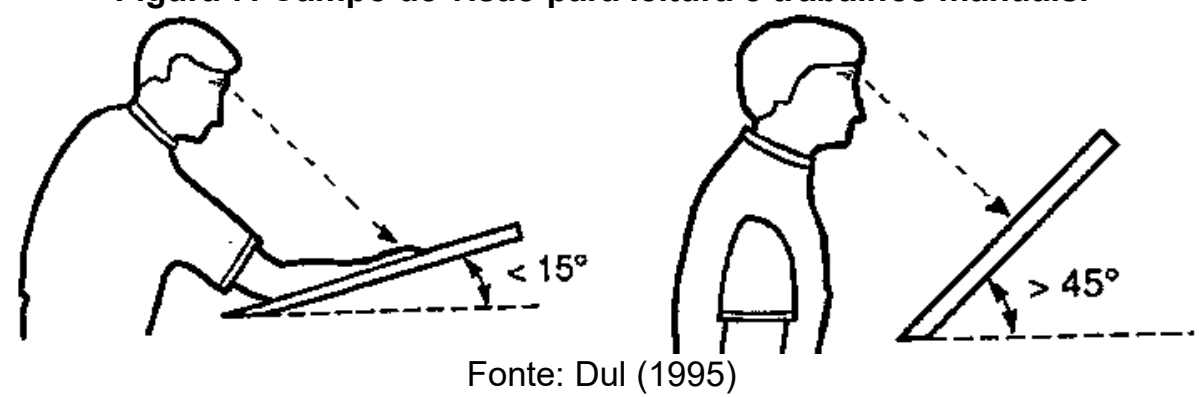

Figura 8: Inclinação do tampo da mesa em $10^{\circ}$ reduz a inclinação do tronco em $9^{\circ}$.
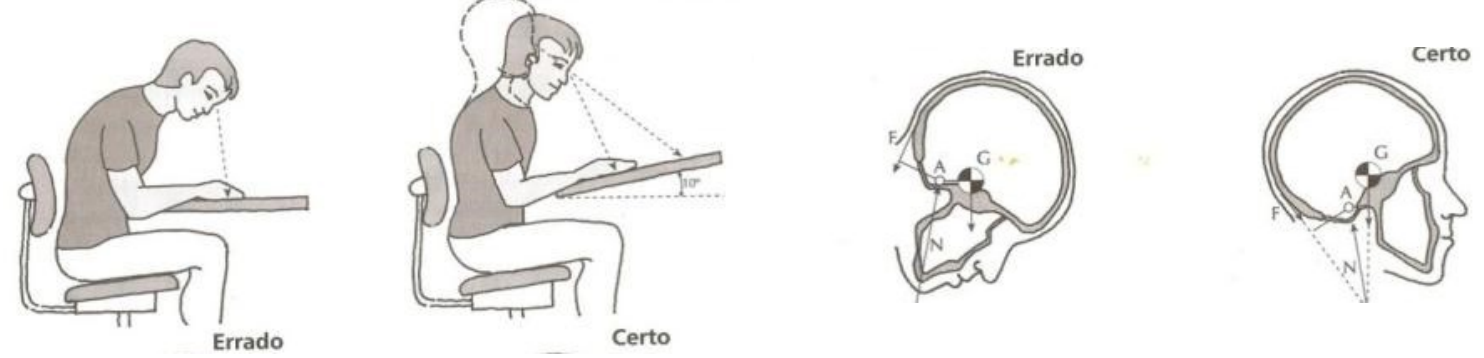

Fonte: lida (2010)

Em virtude dos materiais que os alunos utilizam em aula deslizarem sobre os tampos inclinados, os mesmos nos dias atuais se apresentam nivelados, porém tais superfícies inclinadas representam características benéficas ergonomicamente para a leitura, ou até mesmo para outras atividades. 
O espaço abaixo da superfície de trabalho é muito importante para permitir uma postura adequada sem inclinar o corpo para frente. A largura desse espaço deve ser no mínimo de $60 \mathrm{~cm}$ com uma profundidade na parte superior de pelo menos $40 \mathrm{~cm}$ e de $100 \mathrm{~cm}$ na parte inferior. Isso se deve ao fato de o indivíduo poder mudar de posição de vez em quando.

Figura 9: Espaço mínimo para as pernas, abaixo da superfície de trabalho, na postura sentada.

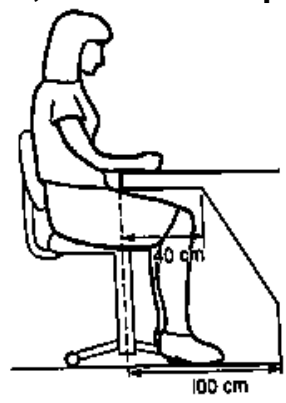

Fonte: Dul (1995)

\subsection{AJUSTE DA ALTURA DO ASSENTO E POSIÇÃO DO ENCOSTO}

Com relação à regulagem de altura dos assentos das cadeiras, destacam-se as seguintes características: regulagem em movimentos contínuos e suaves e não por degraus; possibilitar que a coxa do usuário esteja bem apoiada sem sofrer esmagamento na parte inferior, evitando contato com as bordas do assento e que seus pés estejam apoiados no chão, evitando assim uma postura fatigante; proporcionar apoio para a região lombar no encosto da cadeira, sendo este com uma altura de $30 \mathrm{~cm}$ e um vão livre de 10 a $20 \mathrm{~cm}$ entre o assento e o encosto, totalizando uma altura entre 40 a $50 \mathrm{~cm}$ acima do assento, ressaltando que não deve utilizar esse apoio lombar para apoiar as costas no caso de uma postura relaxada; possibilitar a acomodação da curvatura das nádegas, sendo assim a parte inferior do encosto deve ser convexa ou vazada, aonde o vão livre necessita ser de10 a 20 $\mathrm{cm}$ entre o assento e o encosto, Dul (1995); e finalmente limitar as regulagens da cadeira em apenas no ajuste da altura do assento e na regulagem da altura do encosto, evitando que o usuário faça ajustes indevidos.

\subsection{ANTROPOMETRIA}

A antropometria trata das dimensões e proporções. A ergonomia utiliza técnicas da antropometria com a finalidade de adequar o ambiente de trabalho ao ser humano, bem como em criar objetos que se adaptem ao usuário. Podendo ser classificada como: antropometria estática, antropometria dinâmica, e antropometria funcional. O presente artigo utilizará a antropometria dinâmica que segundo IIDA (2010), as medidas se referem ao corpo parado, ou com poucos movimentos e as medições realizam-se entre os pontos anatômicos claramente identificados.

Para o projeto do mobiliário escolar devem ser observadas pelo menos seis medidas criticas: altura lombar (encosto da cadeira); altura póplite (altura do assento); altura da coxa (espaço entre o assento e a mesa); altura do cotovelo (altura da mesa); altura dos olhos e o ângulo de visão. 


\subsection{MEDIDAS MÍNIMAS E MÁXIMAS: PERCENTIL}

Para evitar erros nas avaliações de medidas, e determinando assim os padrões de tamanhos utiliza-se a grandeza de dissipação das dimensões do corpo humano, sendo tal conceituação determinada como percentil, isto de acordo com Boueri (1991). Para tal fim, segundo Soares e Siqueira (1999), é necessário identificar valores acima ou abaixo dos quais se constata uma determinada porcentagem dos dados. Já Guimarães (2001) constata que percentis dividem uma sequência de quantias em cem partes, cada uma representando à centésima parte da distribuição. Os percentis expõem o número de casos acumulados para os valores achados em cada variável antropométrica, apontando a porcentagem de indivíduos da população que possuem uma medida antropométrica de um tamanho adequado ou menor que este tamanho. Habitualmente, os limites antropométricos de um projeto são expostos em termos de percentis, assim sendo torna-se indispensável seu estudo pelos designers.

O emprego de percentis é um meio de segmentar uma distribuição normal desde o número mínimo até o máximo, conforme uma sucessão ordenada. Os máximos ou mínimos percentis extremos exibem pequena exequibilidade de ocorrência, desse modo, no caso em questão, será dada a média padrão para reprojeto, conforme valores mínimos e máximos de alturas para cadeiras e mesas para escritório, conforme define norma ABNT (Associação Brasileira de Normas Técnicas), NBR 13962 (2002), para móveis e escritórios - Cadeiras e NBR 13966 (1997) para Móveis para escritório - Mesas - Classificação e características físicas e dimensionais.

Tabela 2: Dimensionamentos mínimos e máximos para cadeiras de dimensões das cadeiras fixas.

\begin{tabular}{|c|c|c|c|}
\hline Código & Nome da variável & Valor mín. (mm) & Valor Máx. (mm) \\
\hline a & Altura da superfície do assento* & 400 & 460 \\
\hline$a_{1}$ & Largura do assento & 400 & - \\
\hline$a_{2}$ & Profundidade da superfície do assento & 380 & - \\
\hline$a_{3}$ & Profundidade útil do assento & 380 & 460 \\
\hline$\alpha$ & Ângulo de inclinação do assento* & $-2^{\circ}$ & $-7^{\circ}$ \\
\hline $\mathrm{b}$ & Extensão vertical do encosto & 240 & - \\
\hline $\mathrm{b}$ & Altura do ponto $X$ do encosto* & 170 & 220 \\
\hline $\mathrm{b}$ & Largura do encosto & 305 & - \\
\hline $\mathrm{b}$ & Raio de curvatura de encosto & 400 & - \\
\hline$\beta$ & Ângulo de abertura entre o assento e o encosto & $95^{\circ}$ & $110^{\circ}$ \\
\hline e & Altura do apóia-braço* & 200 & 250 \\
\hline $\mathrm{e}_{1}$ & Distância interna entre os apóia-braços & 460 & - \\
\hline $\mathrm{e}_{2}$ & Recuo do apóia-braço & 100 & - \\
\hline $\mathrm{e}_{3}$ & Comprimento do apóia-braço & 200 & - \\
\hline $\mathrm{e}_{4}$ & Largura do apóia-braço & 40 & - \\
\hline
\end{tabular}

Tabela 3: Dimensões gerais da mesa de trabalho.

\begin{tabular}{clcc}
\hline \multirow{2}{*}{ Código } & \multicolumn{2}{c}{ Nome da variável } & \multicolumn{2}{c}{ "continua" } \\
\cline { 3 - 4 } & & Mínimo $(\mathrm{mm})$ & Máximo $(\mathrm{mm})$ \\
\hline $\mathrm{h} 1$ & Altura da mesa de trabalho & 720 & 750 \\
\hline $\mathrm{I} 1$ & Largura da mesa de trabalho & 800 & - \\
\hline p1 & Profundidade da mesa de trabalho & 600 & 1100 \\
\hline a & Altura livre sob o tampo & 660 & - \\
\hline b & Profundidade livre para os joelhos & 450 & -
\end{tabular}


Tabela 4: Dimensões gerais da mesa de trabalho.

e Largura livre para as pernas

600

"conclusão"

Nota: As dimensões da tabela referem-se a mesas sem regulagem do tampo. As alturas mínimas e máximas para mesas de trabalho com regulagem podem exceder estes limites, desde que contemplem o intervalo indicado.

Fonte: ABNT, NBR 13966 (1997) para Móveis para escritório - Mesas - Classificação e características físicas e dimensionais.

\section{METODOLOGIA}

\subsection{MATERIAL}

O objeto de estudo deste artigo deriva de uma escola de ensino técnico, a qual atende na maioria indivíduos de uma faixa etária média de 22 anos, portanto apresentando um percentil antropométrico entre 1,60 m e 1,67 m de altura para mulheres e 1,72 m e 1,77 m de altura para homens. Além das carteiras escolares, ferramentas digitais, tais como softwares Autocad® do ano 2016 da Autodesk $₫$ e o SketchUp $₫ 2015$ da Trimble $®$, auxiliou para o planejamento da readequação de carteiras escolares.

\subsection{MÉTODOS}

Como foco de estudo, CEGEP é uma escola de cursos técnicos e profissionalizantes localizada na cidade de Mogi Guaçu, interior do Estado de São Paulo, atendendo atualmente 620 alunos, sendo estes moradores da cidade e região.

Figura 10: Localização da escola na qual foram feitos levantamentos fotográficos das carteiras escolares existentes.

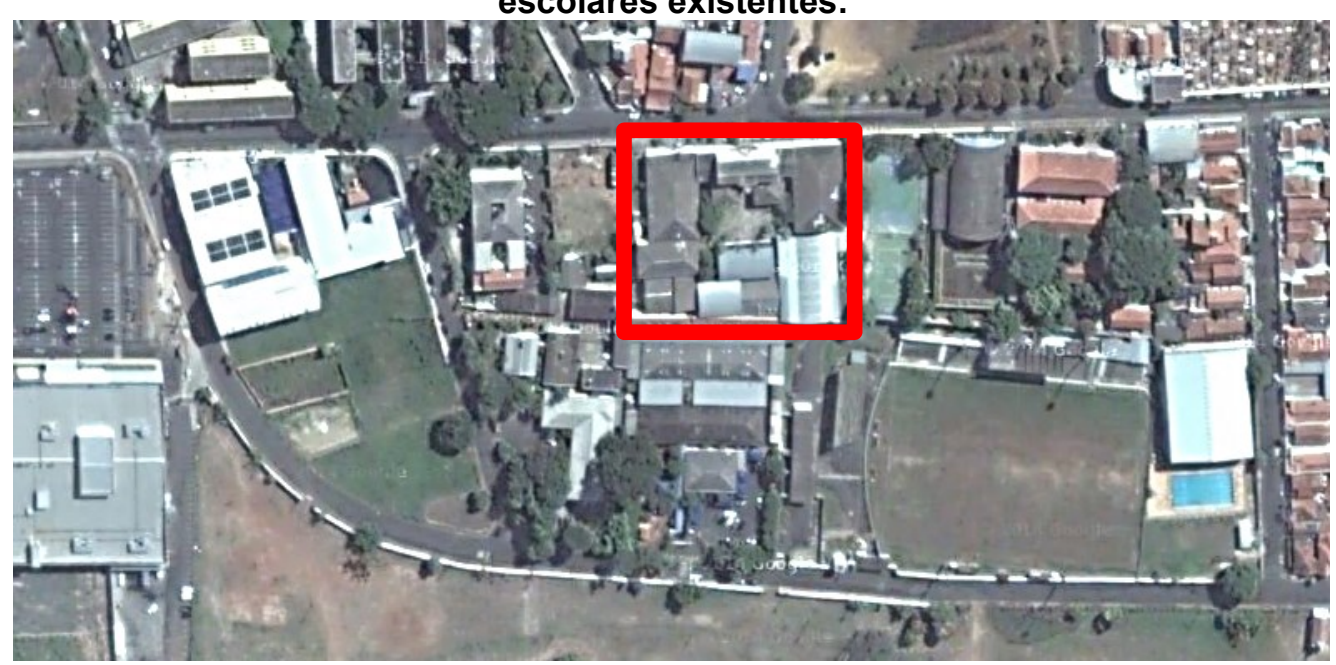

Fonte: Google Maps. (2016)

Levantamentos métricos e fotográficos das carteiras existentes desta instituição de ensino, junto às pesquisas ergonômicas, foram bases comparativas para ressaltar a falta de aspectos e conceitos ergonômicos. 


\subsection{ANÁLISE ERGONÔMICA DAS CARTEIRAS EXISTENTES}

A instituição de ensino Centro de Educação Profissional "Governador Mário Covas" CEGEP possui diversos modelos de carteiras escolares, porém nenhum destes atende as necessidades básicas ergonômicas de seus alunos, ainda mais levando em conta que os mesmos permanecem de três horas e quarenta minutos a quatro horas, sentados na mesma posição na maior parte do tempo.

Nas Figuras 11 A e B, 12 e 13 A e B são ilustradas exemplos de carteiras utilizadas hoje em dia na instituição de ensino em questão.

Figura 11: Carteira Escolar tipo 1 - Imagem lateral e frontal.

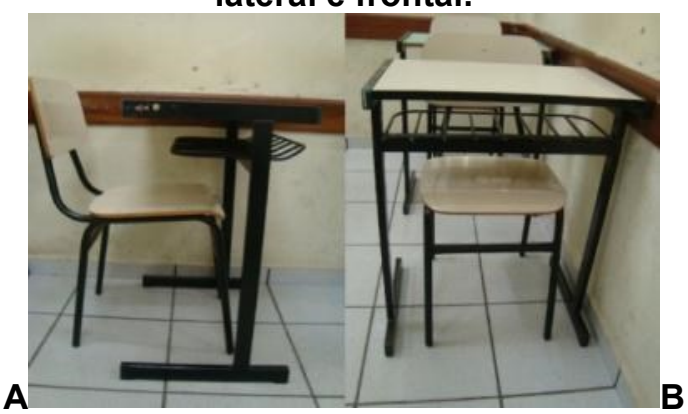

Fonte: Os próprios autores (2015)
Figura 12: Carteira Escolar tipo 2 - Imagem lateral.

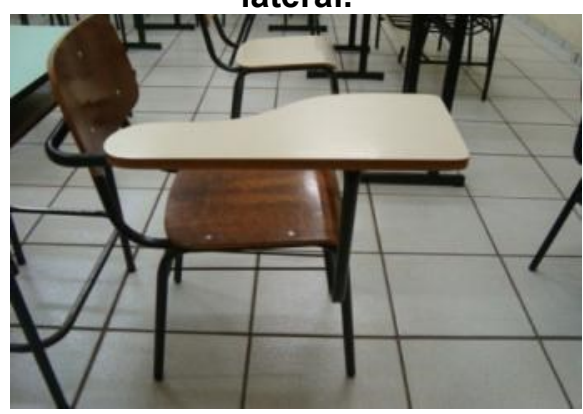

Fonte: Os próprios autores (2015)

Figura 13: Carteira Escolar tipo 2 - Imagem frontal e lateral.

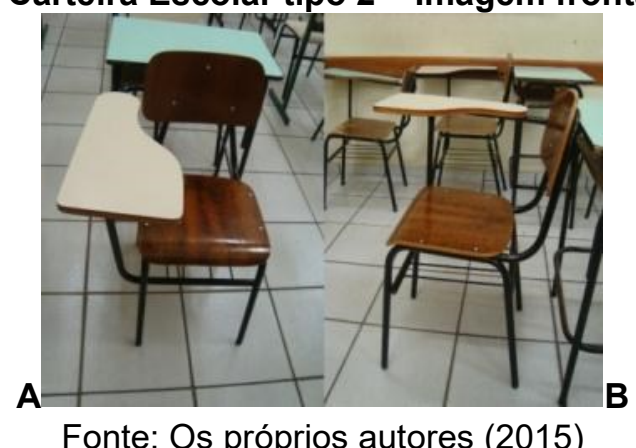

Fonte: Os próprios autores (2015)

Observando as Figuras $11 \mathrm{~A}$ e $\mathrm{B}, 12$ e $13 \mathrm{~A}$ e $\mathrm{B}$, as carteiras existentes na escola não possuem regulagem de altura, nem de cadeira e muito menos de mesa, já em outro exemplo a mesa é associada e fixa a cadeira, não atendendo nem o mínimo exigido na NR 17, que estipula aos mobiliários dos postos de trabalho o seguinte:

a) Trabalho podendo ser executado na posição sentada, o posto de trabalho deve ser planejado ou adaptado para esta posição.

b) Trabalho manual sentado ou em pé, as bancadas, mesas, escrivaninhas e os painéis devem proporcionar condições de boa postura, visualização e operação, atendendo os seguintes requisitos mínimos: Altura e características da superfície de trabalho compatíveis com o tipo de atividade, bem como a distância requerida dos olhos ao campo de trabalho e com a altura do assento; Possuir área de trabalho de fácil alcance e visualização pelo trabalhador; Dispor características dimensionais que possibilitem posicionamento e movimentação adequados dos segmentos corporais.

c) Quando utilizado os pés, os pedais e demais comandos para acionamento pelos pés devem ter posicionamento e dimensões que possibilitem fácil alcance, bem como ângulos adequados entre as diversas partes do corpo do trabalhador, em função das características e peculiaridades do trabalho a ser executado. 
d) Os assentos devem atender aos seguintes requisitos mínimos de conforto: Altura ajustável à estatura do trabalhador e à natureza da função exercida; Características de pouca ou nenhuma conformação na base do assento; Borda frontal arredondada; Encosto com forma levemente adaptada ao corpo para proteção da região lombar.

e) Para as atividades em que os trabalhos devam ser realizados sentados, a partir da análise ergonômica do trabalho, poderá ser exigido suporte para os pés, que se adapte ao comprimento da perna do trabalhador.

Portanto, diante de tais parâmetros e da análise visual é possível constatar que o objeto de estudo não possui suporte para os pés, nem inclinação das mesas, muito menos ajustes de modo algum.

\subsection{RESULTADOS E DISCUSSÃO - PROJETO DA CARTEIRA ESCOLAR}

Após a constatação de como são as carteiras escolares empregadas pela escola, uma readequação será imprescindível para se enquadrar na Norma Regulamentadora 17, sendo assim foram utilizados recursos computacionais para a realização dessa readequação, sendo eles: Software Autocad $\circledast 2014$ para o projeto em planta elevação e Software Sketchup $® 20015$ para modelagem tridimensional.

Como resultado de toda pesquisa obteve-se um projeto de readequação de uma carteira escolar com cadeira e mesa em conformidade com as Normas da ABNT e em padrões ergonômicos satisfatórios, consoante a Norma Regulamentadora $n^{\circ} 17$. Nos assentos e encostos das cadeiras foram utilizados padrão de espuma de densidade normal de escritórios no mercado, assim como a estrutura tubular empregada no projeto é de resistência específica para esse tipo de cadeira e mesa de uso comercial.

Figura 14: Cadeira - Vista lateral esquerda.

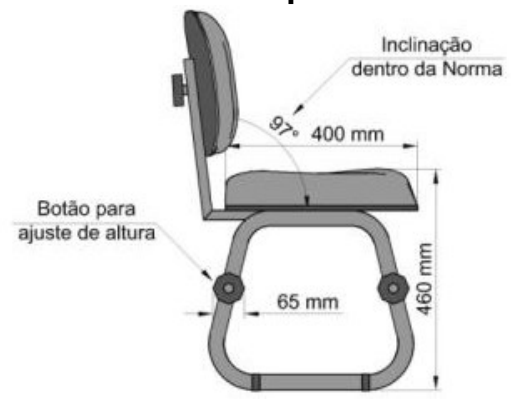

Figura 15: Cadeira - Vista

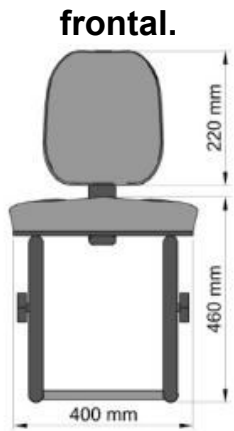

Fontes: Os próprios autores (2015)
Figura 16: Cadeira - Vista posterior.

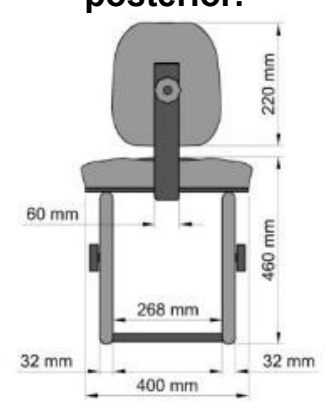

Nas cadeiras e mesas foram colocados dispositivos de regulagem (botão) de altura para que se adapte aos diversos padrões de altura dos usuários, conforme exemplificado na Figura 26, respeitando as Normas da ABNT para mesas e cadeiras de escritório. As mesas ainda contam com ajuste de inclinação para utilização para leitura ou escrita do usuário, assim demonstrado na Figura 18. 
Figura 17: Projeto da mesa - Vista superior.

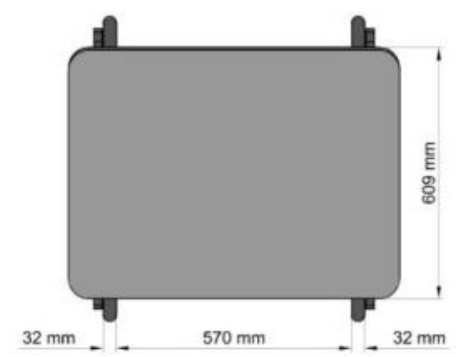

Fonte: Os próprios autores (2015)

Figura 18: Projeto da mesa Vista lateral.

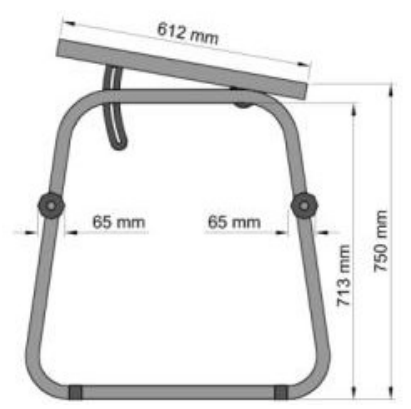

Figura 19: Projeto da mesa Vista frontal.

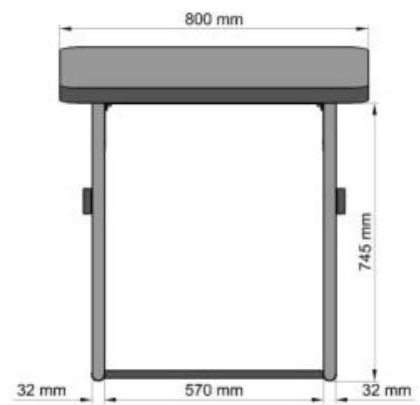

Figura 20: Projeto da mesa Vista posterior.

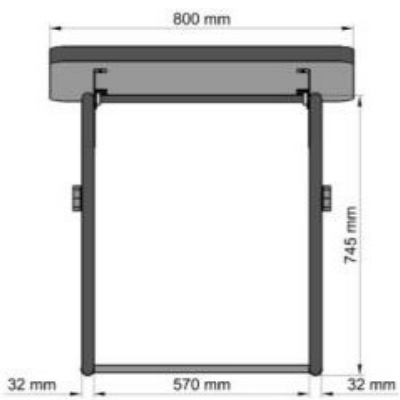

Fontes: Os próprios autores (2015)

Os descansos para os pés possuem movimentação de inclinação livre sobre um eixo interno para que os pés não permaneçam em uma mesma posição, para não comprometer a saúde do usuário.

Figura 21: Descanso para os pés - Vista superior.

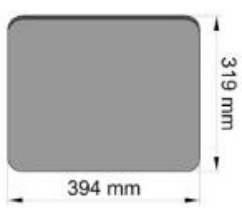

Figura 25: Projeto da carteira escolar: vista superior.

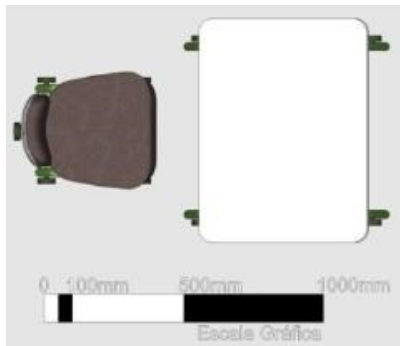

Figura 22: Descanso para os pés - Vista lateral.

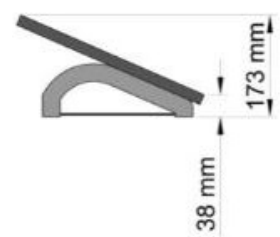

Fontes: Os próprios autores (2015)
Figura 23: Descanso para os pés - Vista frontal.

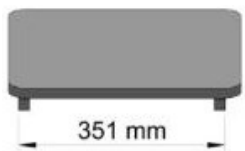

Figura 24: Descanso para os pés - Vista posterior.

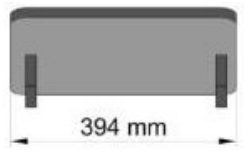

Figura 26: Projeto da carteira escolar: vista lateral esquerda.

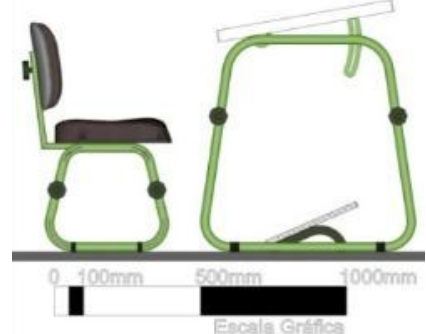

Fontes: Os próprios autores (2015)
Figura 27: Projeto da carteira escolar: vista frontal.

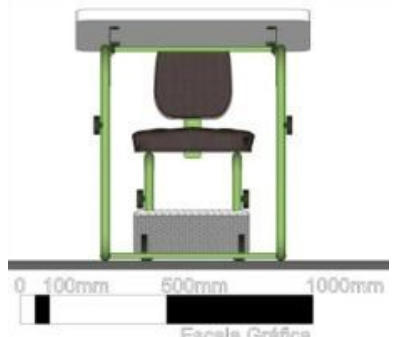


Figura 28: Carteira escolar perspectiva posterior.

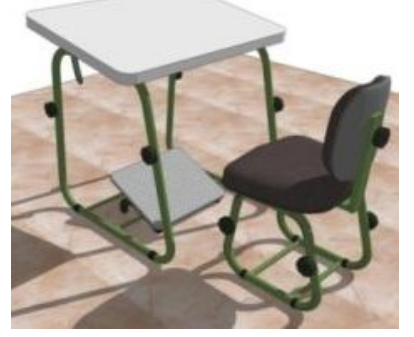

Figura 29: Carteira escolar perspectiva frontal.

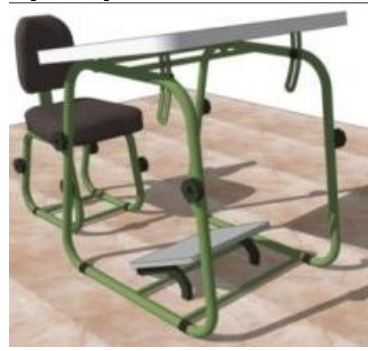

Figura 30: Carteira escolar perspectiva posterior.

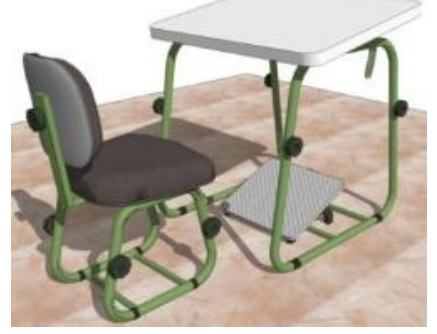

Fontes: Os próprios autores (2015)

Figura 31: Carteira escolar perspectiva superior.

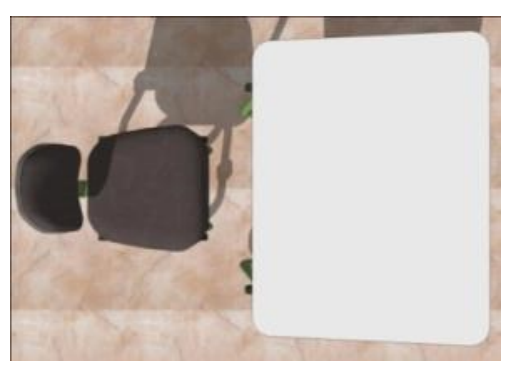

Figura 32: Carteira escolar perspectiva lateral direita.

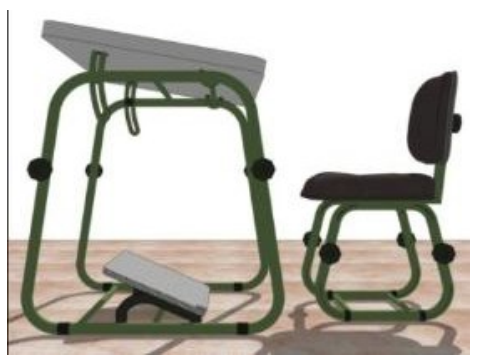

Figura 33: Carteira escolar - perspectiva frontal.

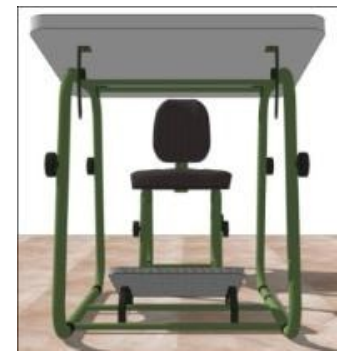

Fontes: Os próprios autores (2015)

\section{CONCLUSÃO}

Em se tratando de saúde e qualidade de vida estudos ergonômicos são fatores de suma importância, que nos dias atuais recebem maior relevância à pesquisa, bem como a elaboração de leis e normas, embasamentos antes ignorados. No entanto estudos sobre ergonomia na adequação de mobiliário escolar notam-se uma carência. Diante das perspectivas observadas, um novo modelo de carteira escolar foi elaborado e reprojetado a partir das problemáticas existentes e dentro das normas pertinentes a esta temática.

De acordo com a Norma Regulamentadora $n^{\circ} 17$ que trata de ergonomia nos postos de trabalho e dentro das normas da Associação Brasileira de Normas Técnicas (ABNT) que impõem mínimos e máximos de dimensões de mesas e cadeiras para escritórios, as carteiras foram readequadas, todo este embasamento resultou em novas carteiras dispostas de regulagens de altura nas mesas e nas cadeiras para proporcionar ao usuário (aluno) um conforto maior devido a suas características antropométricas. Com isso um novo modelo de carteira escolar foi proposto e readequado que em comparação com os já utilizados na escola técnica na qual foi feito o levantamento, supre os requisitos ergonômicos propostos.

\section{REFERÊNCIAS}

Associação Brasileira de Normas Técnicas. NBR 13962: Móveis para escritório - Cadeiras. Rio de Janeiro, 2002. 30 p.

Associação Brasileira de Normas Técnicas. NBR 13966: Móveis para escritório - Mesas. Rio de Janeiro, 1997. 5 p. 
Autodesk - Autocad. Disponível em: <http://www.autodesk.com.br/suites/autocad-designsuite/overview> Acesso em 07 dez. 2014

Autodesk - $\quad$ Autocad. Disponível em: <http://www.autodesk.com.br/products/autocad/overview> Acesso em 07 dez. 2014

BERGMILLER, K. H.; SOUZA, P. L. P de; BRANDÃO, M. B. A. Ensino fundamental: mobiliário escolar. Brasília : FUNDESCOLA - MEC, 1999. 70 p. (Série Cadernos Técnicos I no 3)

BOUERI, J. J. Antropometria aplicada à Arquitetura, Urbanismo e Desenho Industrial. São Paulo, FAU/USP, 1991, v. I.

CASTRO, R. X. S.; Da cadeira às carteiras escolares individuais. Florianópolis, 2009. 111p. Dissertação (Mestrado em Educação) - Universidade do Estado de Santa Catarina.

DUL, J.; WEERDMEESTER, B. Ergonomia Prática. São Paulo: Edgard Blucher, 1995.

GRANDJEAN, E. Manual de ergonomia: adaptando o trabalho ao homem. Porto Alegre: Bookman, 1998. $338 \mathrm{p}$.

Google Maps. Disponível em: <https://www.google.com.br/maps/@-22.3681911,46.9488212,520m/data=!3m1!1e3> Acesso em 06 mai. 2016

GUIMARÃES, L. B. M. Antropometria. Porto Alegre: Programa de Pós-Graduação em Engenharia de Produção da UFRS, 2001.

HIRA, D.S. An ergonomic appraisal of educational desks. Ergonomics, 23 (03): 213-221, 1980.

IIDA, I. Ergonomia: projeto e produção. São Paulo: Edgard Blucher, 2010.

Lei de Diretrizes e Bases da Educação Nacional. Disponível em: < http://www.planalto.gov.br/CCIVIL_03/leis/L9394.htm> Acesso em: 23 abr. 2014.

NORMA REGULAMENTADORA 17. Manual de aplicação da Norma Regulamentadora $\mathbf{n}^{\circ}$ 17. 1.ed., Brasília: MTE, SIT, 2002.

PASCHOARELLI, L. C. O posto de trabalho carteira escolar como objeto de desenvolvimento da educação infantil: uma contribuição do design e da ergonomia. Bauru, 1997. 136 p. Dissertação (Mestrado em Desenho Industrial) - UNESP.

Sketchup. Disponível em: <http://www.sketchup.com/pt-BR> Acesso em 15 dez. 2014

SOARES, J. F.; SIQUEIRA, A. L. Introdução à estatística médica. Belo Horizonte: Departamento de Estatística - UFMG, 1999. 